\title{
Itinerários vividos, histórias narradas: gradientes de autonomia entre beneficiários do Programa 'De Volta para Casa'
}

\author{
Lived itineraries, narrated stories: the autonomy gradients among \\ beneficiaries of the 'Back Home Program'
}

Alyne Silva', Aleff Aleixo ${ }^{\mathbf{2}}$, Camilla Silva $\mathbf{3}$, João Duarte', Maristela Moraes ${ }^{\mathbf{1}}$

DOI: $10.1590 / 0103-1104202012711$

RESUMO Este trabalho parte de uma pesquisa multicêntrica que abrange 11 municípios que sofreram intervenção federal para o fechamento dos seus hospitais psiquiátricos e lançaram mão do Programa 'De Volta para Casa' (PVC) como estratégia de desinstitucionalização. Inspirados metodologicamente pela etnografia e metodologia de história de vida, realizou-se o acompanhamento dos itinerários dos primeiros beneficiários do PVC em um município paraibano e, a partir de observação participante e trocas diretas com eles, produziram-se narrativas orientadas por quatro eixos de análise: 1) Trajetória de vida; 2) Autonomia: emancipação x opressão; 3) O que o capital faz poder; 4) Acesso à saúde, acesso à vida. O objetivo foi compreender os efeitos deste auxílio- reabilitação na construção de autonomia de seus beneficiários, em seus diferentes graus. Entendendo autonomia enquanto capacidade do sujeito de construir vínculos em conjunto com outras pessoas e lidar com sua rede de dependências, apresentaram-se diferentes graus de autonomia expressos pelos beneficiários do PVC, partindo da centralidade desse conceito e do tensionamento que provoca. Percebeu-se que há muitas formas e graus de autonomia entre os beneficiários acompanhados, o que depõe contra a visão liberal hegemônica de autonomia.

PALAVRAS-CHAVE Autonomia pessoal. Reforma dos serviços de saúde. Desinstitucionalização.

1 Universidade Federal de Campina Grande (UFCG) - Campina Grande (PB), Brasil.

alvarezalyne@gmail.com

2 Universidade Federal da Paraíba (UFPB) - João

Pessoa (PB), Brasil.

3 Universidade Estadual da Paraíba (UEPB) - Campina Grande (PB), Brasil.
ABSTRACT This work starts from a multicenter research that covers eleven cities that suffered federal intervention to close their psychiatric hospitals and have used the 'De Volta para Casa' Program (PVC Back Home Program) as a deinstitutionalization strategy. Methodologically inspired by ethnography and life history methodology, we followed the itinerary of the first beneficiaries of PVC in a city in Paraíba, and from participant observation and direct exchanges with them, we produced narratives guided by four axes of analysis:1) Life Trajectory;2) Autonomy: emancipation x oppression; 3) What capital provides; 4) Access to health, access to life. Our goal was to understand the effects of this rehabilitation aid on the reconstruction of beneficiaries' autonomy, in its different degrees. Understanding autonomy as the subject's ability to build bonds with other people and deal with his dependency network, we present different degrees of autonomy expressed by PVC beneficiaries, starting from the centrality of the concept and the tension that it causes. It was noted that there are many ways and degrees of autonomy, which testifies against the hegemonic liberal view of autonomy.

KEYWORDS Personal autonomy. Health care reform. Deinstitutionalization. 


\section{Introdução}

No campo da saúde mental, em quase quatro décadas de luta antimanicomial, desde o início das problematizações, no final da década de 1970 - que deram origem ao Movimento dos Trabalhadores da Saúde Mental e, posteriormente, aos Movimentos da Luta Antimanicomial (Movimento Nacional de Luta Antimanicomial - MNLA e Rede Nacional Internúcleos da Luta Antimanicomial - Renila) - até o final de 2015, teve-se significativo avanço na construção e implementação de uma Política Nacional de Saúde Mental, Álcool e Outras Drogas, pautada na defesa, promoção e garantia dos direitos humanos da população com diagnóstico de transtorno mental ou em sofrimento psíquico, o que há pouco tempo também entrou no rol dos retrocessos.

Após anos de luta contra saberes e práticas médico-centrados e hospitalocêntricos, até então, hegemônicos, a Reforma Psiquiátrica Brasileira (RPB) se consolida com a aprovação da Lei no ${ }^{0} 10.216 / 2001^{1}$, que dispõe sobre a proteção e os direitos das pessoas portadoras de transtornos mentais e redireciona o modelo assistencial em saúde mental, dando base à Política Nacional de Saúde Mental. À Lei da Reforma Psiquiátrica, soma-se a Convenção sobre os Direitos da Pessoa com Deficiência (CDPD) ${ }^{2}$, assinada pelo Brasil, em 2008, e regulamentada pela Lei Brasileira de Inclusão da Pessoa com Deficiência ${ }^{3}$, destinada a assegurar e a promover, em condições de igualdade, $o$ exercício dos direitos e das liberdades fundamentais da pessoa com deficiência, visando à sua inclusão social e cidadania. É importante dizer que, por pessoa com deficiência, entende-se:

[...] aquela que tem impedimento de longo prazo de natureza física, mental, intelectual ou sensorial, o qual, em interação com uma ou mais barreiras, pode obstruir sua participação plena e efetiva na sociedade em igualdade de condições com as demais pessoas ${ }^{2}$.
Além dos avanços legislativos, na dimensão técnico-assistencial da RPB, viu-se a expansão da Rede de Atenção Psicossocial (Raps) ${ }^{4}$, com a implantação de vários serviços substitutivos territoriais que a compõem, em especial, o Centro de Atenção Psicossocial (Caps), o qual contava, em 2015, com 2.328 unidades em todo o território nacional4 ${ }^{4}$. A expansão da Raps se deu em paralelo ao fechamento de mais de 60 mil leitos psiquiátricos/Sistema Único de Saúde (SUS), entre os anos de 1994 e 2014,5, bem como a implementação de outros dispositivos de garantia/restituição de direitos previstos na Portaria $n^{0} 3.088 / 2011^{6}$, do Ministério da Saúde, que institui a Raps para pessoas com sofrimento ou transtorno mental e com necessidades decorrentes do uso de crack, álcool e outras drogas, no âmbito do SUS.

Um desses dispositivos é o auxílio-reabilitação, instituído pela Lei ${ }^{0} 10.708 / 2003^{7}$, que integra um programa de ressocialização denominado Programa 'De Volta para Casa' (PVC) e que prevê, atualmente, o recurso de $\mathrm{R} \$ 412,00$ a quem esteve por dois anos ou mais internado em instituições de longa permanência, visando à sua reabilitação psicossocial. Na Portaria ${ }^{\circ}$ 3.088/2011, o PVC é entendido como Estratégia de Desinstitucionalização e descrito como "uma política pública de inclusão social que visa contribuir e fortalecer o processo de desinstitucionalização" (\$ $3^{\circ}$, art. 11) ${ }^{6}$.

De modo geral, desinstitucionalização é o processo crítico-prático para a reorientação de todos os elementos constitutivos das instituições voltadas para loucura, objeto que, irredutível a uma doença, deverá ser entendido enquanto "existência-sofrimento da pessoa em sua relação com o corpo social" segundo Rotteli8(91). De acordo com o mesmo autor, desinstitucionalização seria "o processo prático-clínico que reorienta instituições e serviços, energias e saberes, estratégias e intervenções em direção a este tão diferente objeto"8(91). Portanto, processo permanente de questionamento e superação das estruturas e lógicas manicomiais pari-passu à invenção de outras práticas, saberes e relações que busquem 
acompanhar o fluxo mutante da vida e suas condições de existência a partir do princípio fundamental do cuidado em liberdade.

De modo mais pontual, desinstitucionalizar, para além do simples sentido de retirar alguém da instituição asilar, significa restituí-la dos direitos fundamentais para a sua reprodução social, para uma vida digna em sociedade. Nesse sentido, os componentes de desinstitucionalização previstos na Portaria n ${ }^{0}$ 3.088/2011 são os Serviços Residenciais Terapêuticos (SRT) e o PVC, ou seja, moradia e renda/benefício, dois direitos fundamentais para o exercício da cidadania.

O PVC busca garantir poder de contratualidade àqueles que estiveram à margem da sua condição de cidadania na medida em que, além do direito à cidade, da ampliação do circuito de circulação pelo território, possibilita um poder de barganha para a vida na sociedade de consumo em que se vive. A autonomia também deve ser consequência desse dispositivo, considerando a necessidade de que as pessoas egressas de manicômios retomem ou construam, a partir do benefício, possibilidades de identificação das suas necessidades e potencialidades para saná-las minimamente.

Tendo em vista a importância do PVC para a efetivação da RPB, em 2016, a Fundação Oswaldo Cruz (Fiocruz) propôs parcerias com grupos de pesquisa de algumas universidades públicas para executar o projeto de pesquisa intitulado 'O Programa De Volta Para Casa e a desinstitucionalização: o impacto na vida cotidiana dos beneficiários'. A pesquisa abrangeu a realidade de 11 municípios brasileiros que sofreram intervenção federal para o fechamento dos seus respectivos hospitais psiquiátricos, todos com péssimas avaliações no Programa Nacional de Avaliação dos Serviços Hospitalares (PNASH) naquele período. As intervenções federais foram cuidadosamente construídas entre 2004 e 2005.

Aos egressos dos hospitais psiquiátricos fechados, foi garantido o auxílio-reabilitação do PVC. Além do PVC, nos municípios que sofreram intervenção federal, houve a implantação de SRT destinados aos egressos; a abertura de Caps com atendimento 24 horas; e a formação específica para trabalhadores e trabalhadoras da saúde mental, com base nos princípios da Reforma Psiquiátrica.

Em um município da Paraíba, o Hospital Psiquiátrico fechado funcionou por 44 anos e chegou a abrigar até 200 internos, sendo a maioria deles custeados com recursos públicos. Na época do seu fechamento, o manicômio havia sido avaliado como um os piores do Brasil, oferecendo:

Condições extremamente desumanas, como falta de colchões e roupas, falta de água, alimentos estragados servidos, banhos coletivos com mangueira, entre outras situações inaceitáveis9(4).

O fechamento do Hospital teve pouco apoio popular, apesar das denúncias públicas feitas pelos interventores, pois políticos, familiares de pacientes e outros segmentos da população daquela cidade temiam um aumento da violência produzida por tal população quando posta em liberdade ${ }^{10}$.

Desde a intervenção, ocorrida em 2005, a Raps do município cresceu substancialmente e hoje:

Conta com 08 CAPS (sendo dois nos municípios vizinhos), dos quais 02 são 24 horas (um deles é um ad infanto-juvenil), 06 Residências Terapêuticas, um Centro de Convivência Cultural, um Chalé de Artesanatos da Saúde Mental em um mercado de artesanato da cidade, além de leitos especializados em hospital geral municipal (doze para adultos e oito para crianças e adolescentes). O município conta com uma referência técnica dos Serviços Residenciais Terapêuticos que também atua como coordenadora do PVC(4-5).

Como parte da produção dessa pesquisa da Fiocruz acima citada, realizou-se o acompanhamento dos itinerários de dez beneficiários, ao longo de aproximadamente quatro meses 
(novembro de 2017 a fevereiro de 2018), como preconizava o desenho metodológico da pesquisa nacional, orientado pelos princípios da RPB. Optou-se por obter o consentimento de todos, na medida da sua capacidade de expressar a permissão, bem como propôs-se o acompanhamento das pessoas nos territórios de liberdade proporcionados também pela pesquisa, entendida como parte da rede de proteção a seus modos peculiares de existência.

Assim, para além da análise dos impactos do PVC na vida de seus primeiros beneficiários, que em algum nível garantiram o aumento da contratualidade e da autonomia dos sujeitos, viu-se que a própria pesquisa disparou efeitos nessa direção em virtude do modo como os pesquisadores propuseram aproximação e construção conjunta da pesquisa. Ficou evidente o aumento da autonomia dos beneficiários do PVC também como efeito da relação orientada pelos princípios éticos da RPB, base de formação dos pesquisadores.

Nesse sentido, visou-se com este artigo apresentar diferentes graus de autonomia expressos pelos beneficiários do PVC, acompanhados na referida pesquisa, partindo da centralidade do conceito de autonomia. Para tanto, utilizaram-se trechos de duas das narrativas construídas na pesquisa.

\section{Metodologia}

Como já mencionado, o presente artigo é um recorte de uma pesquisa multiterritorial, inspirada na etnografia e na metodologia de história de vida, na qual se utilizaram três procedimentos metodológicos: produção de narrativas a partir do encontro e do acompanhamento dos itinerários de beneficiários; entrevistas com atores estratégicos que atuaram à época do fechamento do manicômio local; e a constituição de um Comitê de Acompanhamento da Pesquisa (CAP), com o objetivo de discutir, sistemática e coletivamente, os caminhos a serem tomados no decorrer da pesquisa.

Considerando o objetivo proposto para a elaboração deste artigo, optou-se por utilizar apenas o que foi construído no encontro entre pesquisadores, pesquisadoras e beneficiários: as narrativas. Enquanto produtos encomendados pela pesquisa nacional, as narrativas foram definidas como produções textuais sobre a vida dos primeiros beneficiários do PVC, daquele município, produzidas a partir da observação participante e diálogo direto com os beneficiários, orientadas pelos seguintes eixos de análise: 1) Trajetória de vida; 2) Autonomia: emancipação x opressão; 3) O que o capital faz poder; 4) Acesso à saúde, acesso à vida.

Para Lacerda e Guzzo", o Método de Histórias de Vida (MHV) procura apreender o conteúdo e os aspectos subjetivos relativos à descrição da própria vida por parte do sujeito; isso subsidiou o recurso a essa metodologia para cobrir os eixos e, em especial, o primeiro. À medida que se narra a própria história, os sujeitos dão novos sentidos, ressignificam e se reposicionam diante da própria história, analisando por novas perspectivas os eventos vividos. A história de vida narrada produz um conjunto de passagens que podem ser decompostas e analisadas com vistas à identificação de posições e papéis exercidos pelos sujeitos em situações histórico-concretas. Há de se observar as particularidades na apropriação desse método: dada a condição de alguns dos atores acompanhados, $\mathrm{o}$ acesso às suas histórias de vida só foi possível mediante o contato com seus parentes mais próximos, de modo que algumas das histórias narradas na pesquisa são produtos do entrelaçamento de relatos e perspectivas distintas.

Para a observação participante e para o diálogo direto com os beneficiários e com suas famílias e cuidadores - bem como para a escrita dos diários de campo - utilizaram-se 15 questões norteadoras. Elas foram desde os aspectos da vida atual - tais como saúde, moradia, educação, gostos pessoais, experiências do cotidiano, relações interpessoais, relação com o cuidado, acesso à cidade e as trocas nela realizadas - passando pelo uso do benefício e, para além disso, a compreensão do beneficiário com relação a este e, 
por fim, explorando questões outras, como experiências passadas - as moradias pelas quais passaram, por exemplo - além de buscar compreender a relação dos beneficiários com a Raps. Assim, tais questões foram propostas como modo de orientar os olhares dos pesquisadores em cada encontro e, assim, facilitar a construção das narrativas, de acordo com seus quatro eixos. As questões orientaram a produção das narrativas e a construção de um princípio de análise sobre o impacto do PVC na vida dos beneficiários.

A imersão no campo guiados pelo método etnográfico ${ }^{12}$ colocou os investigadores diante da abertura para a relação com as pessoas beneficiárias do PVC e suas experiências de vida, assim como garantiu a observação e a troca direta com elas nos seus locais de moradia - fossem estes locais as Residências Terapêuticas (RT), fossem as casas de familiares e/ou responsáveis por aqueles que não moravam sozinhos - e, quando possível, em seus espaços de trânsito.

Das dez narrativas escritas, uma para cada um dos dez beneficiários acompanhados ao longo do percurso da pesquisa, escolheram-se apenas duas para problematizar o conceito de autonomia. Tal delimitação se deu, primeiramente, a partir dos próprios limites concernentes ao trabalho aqui proposto. Além disso, a definição das histórias que são utilizadas enquanto ponto de partida para a discussão foi feita de maneira aleatória, entre aquelas que haviam sido escritas por, pelo menos, uma das pessoas pesquisadoras que compõem a autoria deste trabalho, já que o grupo de pesquisadores ea mais extenso.

Em todas as narrativas, trabalhou-se com pseudônimos criados a partir da história de cada beneficiário - pelo seu apreço por algum personagem conhecido, por seus gostos musicais, por seu modo de se relacionar com as pessoas, entre outros aspectos subjetivos que surgiram no decorrer dos encontros. As narrativas foram escritas ao longo de, em média, dez encontros entre cada beneficiário e pesquisadores/as, registrados em diários de campo. O período de quatro meses para a coleta das informações e o número de encontros realizados com cada beneficiário não foram predeterminados. A orientação da coordenação nacional era buscar responder as 15 perguntas norteadoras e alinhavar as narrativas a partir dos 4 eixos de análise. $\mathrm{Na}$ medida em que pesquisadores se sentiam contemplados com respostas suficientes para ambos os critérios, poderiam sinalizar aos beneficiários que teriam apenas mais um ou dois encontros para encerrar a pesquisa.

As narrativas apresentadas neste artigo, portanto, apesar de escritas pelos pesquisadores, foram tecidas considerando as falas dos beneficiários enquanto narradores de sua própria história. Isto é, durante o acompanhamento dos seus itinerários terapêuticos, dialogou-se e perguntou-se sobre suas experiências nos hospitais psiquiátricos e, para além disso, sobre suas vidas após a saída. No decorrer da pesquisa, considerou-se a compreensão dos itinerários terapêuticos que dizem das experiências das pessoas e famílias - e aqui se pensam, de maneira ampliada, as suas redes sociais - em seus modos de significar e produzir cuidado "empreendendo trajetórias em diferentes redes que possam lhes dar sustentabilidade nessa experiência"13(185). Assim, enxergam-se, no itinerário terapêutico, as potencialidades que há nos encontros. Atenta-se para o que circula nas relações.

Nesse sentido, para guiar e dar corpo à discussão aqui proposta, destacam-se, de duas narrativas escritas no âmbito da pesquisa, alguns trechos que dão pistas sobre uma compreensão ampliada de autonomia.

\section{Discussões sobre a autonomia a partir das narrativas}

Entender os vários gradientes de autonomia, cujos limites estão constantemente tensionados, não havendo, como nos dizem Onocko e 
Campos ${ }^{\mathbf{1 4}}$, uma autonomia pronta e aplicável para todos, foi um exercício potencializado pelos encontros e pela interlocução com os beneficiários do PVC que foram acompanhados na pesquisa.

Na mesma direção, dada a importância dessa articulação para entender de forma ampliada a autonomia, ocupou-se também dos modos como a contratualidade está presente na vida dessas pessoas nas suas relações de intercâmbio social, de trocas sociais, com atenção à desconstrução (ou não) do dispositivo manicomial como o lugar da troca zero. Para além da estrutura física dos muros e grades, também se atentou aos manicômios mentais"1 que continuam invalidando a possibilidade de as pessoas romperem os estigmas e os preconceitos próprios de uma sociedade contratual burguesa, calcada na razão e no pretensioso desejo de controle e previsão dos acontecimentos ${ }^{15}$.

Ocupar as ruas como um leão que foge do seu domador, escolher que tipo de roupa é melhor usar dentro e fora dos muros de casa (RT), escolher a comida ou delimitar que apenas o próprio pai realize sua higiene pessoal. Quais dessas escolhas e/ou manifestações da vontade podem ser compreendidas, no esmiuçar do cotidiano, enquanto expressões de autonomia? Todas ou só aquelas que sinalizam processos dinâmicos em que saúde e autonomia implicam perdas ou aquisições gradativas ${ }^{15}$.

Kinoshita ${ }^{15(71)}$ alerta que, por um lado, a autonomia pode ser entendida como "a capacidade de gerar normas/ordens para si de acordo com as circunstâncias da vida", concepção que leva a pensar na autonomia como autossuficiência ou independência para seu exercício.

A suposta capacidade do sujeito assenhorar-se de si e criar normas para sua própria vida parte de uma concepção iluminista/liberal de sujeito: este, dotado de razão e dispondo do máximo de informações possíveis, é o único capaz de deliberar sobre o próprio destino, livrando-se de intervenções ou coações externas, sejam elas provenientes das pessoas do seu convívio, da comunidade em que se está inserido ou do próprio Estado.

É uma concepção individual de autonomia que, tendo na razão um de seus principais fundamentos, subsidiou a segregação e o controle daqueles cujas condutas eram tidas como desarrazoadas. É uma versão de autonomia que se adequa, em larga medida, aos ditames do neoliberalismo, cuja racionalidade, conforme a análise empreendida por Dardot e Laval ${ }^{16}$, tem como objetivo o fomento de subjetividades individualistas, hipercompetitivas, que tomam o outro como um adversário e têm a si mesmas como indivíduos-empresa, em um cenário em que a comunidade e a sociedade em que se está inserido não é mais que um pano de fundo para a ação racional e individual.

A partir disso, cabe inferir que é no elemento indivíduo-empresa que a racionalidade neoliberal se impõe com mais força na vida dos beneficiários acompanhados pela pesquisa. Muitas vezes, a gestão de SRT, bem como amplos setores da sociedade, consideram autônomos apenas aqueles que apresentam, de acordo com os critérios da gestão, maiores níveis de independência (ou seja: dependência apenas de si mesmos) e facilidade no trato com o dinheiro advindo dos benefícios aos quais têm acesso. Essa 'facilidade' é expressa naqueles que usam o seu capital em conformidade com o que a gestão espera.

Os beneficiários acompanhados não dispõem do valor integral do benefício, cuja posse está com a gestão sob a justificativa de, valendo-se do dinheiro, prover serviços de saúde que não estão disponíveis no SUS e outras atividades de lazer. Alguns deles recebem, semanalmente, uma parte do dinheiro para utilizar como julgarem adequado. É o caso de Roberto Carlos, considerado pela gestão como um dos beneficiários mais autônomos, que está entre os que recebem a 'mesada':

Do valor de $R \$ 412,00$ do auxílio- reabilitação do qual é beneficiário, devido ao cadastro no $P V C$, Roberto recebe um valor por semana, o qual repassa parte para a sua mãe. $O$ restante 
do benefício é gerido pela gestão do Programa e utilizado para necessidades extras que venham a surgir, como, por exemplo, a necessidade de realizar algum exame que não é disponibilizado pelo SUS ou, ainda, passeios, dentre outras atividades que possam surgir. (Narrativa Roberto Carlos).

Roberto Carlos, personagem em questão, é um dos beneficiários que são 'contemplados' com uma mesada semanal, por ser considerado um dos moradores mais autônomos dos SRT da cidade. Sua tranquilidade e maturidade características sempre ressaltadas por quem lhe rodeia - seu jeito caseiro e sua relação com o dinheiro, marcada por um manuseio consciente, não são considerados problemáticos, o que gera o entendimento de que está apto a receber, em mãos, sua mesada - que não é a integralidade do que, por direito, deveria receber.

A narrativa de Roberto, conforme citado, permite perceber que, embora os valores recebidos sejam limitados - tanto em quantia, quanto em periodicidade -, o beneficiário viabiliza sua participação direta nos custos gerados a cada visita que faz à casa de sua mãe. Quando questionado sobre o valor que recebe, embora não compreenda prontamente do que se trata o PVC,

atina para o modo como utiliza seu dinheiro: 'levo lá pra minha mãe'. Ela gasta com ele. Compra seu cigarro, 'compra um pãozinho', faz café e ele toma quantas xícaras desejar. (Narrativa Roberto Carlos).

O beneficiário expõe com satisfação essa relação que é estabelecida com sua mãe. O vínculo é garantido não pelo dinheiro, mas pela relação de troca que é proposta pelo filho e acatada pela mãe. Observa-se que, à medida que as relações entre os pesquisadores e beneficiários se tornavam mais próximas, tornou-se mais fácil identificar sutis movimentos que diziam de uma vontade própria que, principalmente em suas residências, fazia-se respeitar, dando pistas sobre os vários gradientes de autonomia sobre os quais se trata no presente artigo.
Tais movimentos não se limitavam somente às suas residências. Ao contrário, quando tinham acesso à rua, ao parque ou, ainda, à feira - embora nem todos tivessem trânsito livre, algo que foi definido e sustentado pela gestão a partir da compreensão que coloca as pessoas no lugar de 'capacidade' ou da ausência dela - os beneficiários atravessavam algumas barreiras impostas pelas normas e consumiam, por exemplo, os alimentos que desejavam com o valor que tinham em mãos. A exemplo disso, pode-se mencionar um momento no qual uma das pessoas pesquisadoras estava tomando um café da tarde na companhia de alguns beneficiários, em uma das residências, e notou que um dos moradores estava lanchando algo diferente dos demais. Era um bolo que, de acordo com algumas regras de alimentação da RT, não deveria, segundo orientação médica, ser consumido por todos - inclusive pelo beneficiário que o portava. Contudo, ele havia chegado de uma caminhada após uma consulta médica e, segundo a cuidadora que o acompanhava, ainda na rua, parou em uma mercearia e, com o dinheiro que carregava consigo, adquiriu o lanche que desejava.

A produção de autonomia(s), a partir da singularidade de cada beneficiário, vai se mostrando em seu caráter de pluralidade. Alguns optam por dormir a qualquer hora do dia - o que os desloca dos horários padronizados típicos das instituições asilares ${ }^{\mathbf{1 7}}$ - outros evidenciam quando não estão a fim de conversar ou participar de alguma atividade coletiva. Há ainda o beneficiário que tem uma namorada e lida bem com o fato de dizerem que ela se relacionou com outras pessoas. Outro prefere chás a remédios. Se, muitas vezes, não é permitido definirem o que comerão a cada refeição, há a possibilidade de negar, cada um ao seu modo, aquilo que não toleram. Há, pois, um movimento gradual que vai se fazendo aparente e que permite inferir que

Roberto [e outros companheiros] brinca numa gangorra de autonomia que ora lhe coloca no lugar de detentor de escolhas, ora no de pessoa que 
recebe ajuda da pedagoga para apagar um erro comum cometido ao escrever. (Narrativa Roberto Carlos).

Há que se adotar, aqui, portanto, uma concepção de autonomia que verse sobre a vida em comum e suas possibilidades, entendendo que o humano se faz e refaz a partir do reconhecimento mútuo entre pares, construindo uma vida e galgando possibilidades que só são viáveis a partir da partilha e do convívio entre os seus, tendo o público - e não só o privado - como um campo importante de ampliação da liberdade.

Nesse sentido, na contramão do paradigma neoliberal, tem-se a autonomia como capacidade de estabelecer, em um plano comum de coexistência, relações de interdependência para a construção das escolhas e decisões de modo ético, isto é, decisões que podem ser apoiadas e cujos efeitos considerem sua existência na relação com os demais que o cercam. Retomando Kinoshita ${ }^{15}$, o fato de as relações das pessoas diagnosticadas com transtorno mental serem geralmente muito restritas é o que as tornam menos autônomas. Segundo o autor,

somos mais autônomos quanto mais dependentes de tantas coisas pudermos ser, pois isto amplia nossas possibilidades para o estabelecimento de novas normas, novos ordenamentos para a vida15(57)

É com essa perspectiva que se tem dialogado. Não se toma esse conceito como o antônimo de dependência ou como liberdade absoluta, como já sinalizado, devido à sua aproximação à compreensão individualista/ liberal. Ao contrário, entende-se autonomia como a capacidade do sujeito, em sua relação com o corpo social, de construir redes de dependências: de apoio, proteção, afetos ${ }^{\mathbf{1 4}}$.

Sobre as redes de sociabilidade, tão importantes nessa interdependência necessária para a construção da autonomia que aqui se defende, destaca-se que, entre os beneficiários acompanhados, as redes de sociabilidade ainda são restritas e circulam quase que exclusivamente em torno dos moradores das mesmas RT e nos outros serviços de saúde que frequentam ou, no caso do beneficiário que vive com a família, ao salão de cortar cabelo ou ao contato com um vizinho bem próximo. Obviamente, entre os companheiros de casa (RT em quase todos os casos) e com os familiares, há vínculos fortes, de cuidado e respeito, que se estendem aos cuidadores e cuidadoras das RT e às gestoras da saúde, mas não custa destacar que esses repertórios relacionais podem ser ainda mais ampliados.

Certo dia, conta com ar de riso, esteve no Parque da Criança com seus colegas e lá pôde chupar um picolé e 'tomar um pequeno' [um café]. Esse pequeno surgiu de um pedido que fez para uma senhora que estava ali por perto. (Narrativa Roberto Carlos).

É importante que se diga que a CDPD² inaugurou um novo paradigma para pensar a concepção de ser humano a partir das necessárias relações de interdependência com o mundo para o exercício da autonomia ${ }^{16}$. Autonomia esta que pode se dar com apoio de outra(s) pessoa(s) para que a pessoa com deficiência, que historicamente teve sua capacidade de decisão negada, venha a decidir sobre sua própria vida e realizar escolhas que respondam às suas necessidades.

A tomada de decisão apoiada é imprescindível para o exercício da capacidade legal prevista no art. 12 da Convenção, refletida no art. 85 da Lei Brasileira de Inclusão ${ }^{\mathbf{1 6}}$, e permite a compreensão emancipatória de que pessoas com deficiência podem ter apoio para o exercício da sua capacidade sem que isso as diminua como pessoas, como cidadãs. Essa discussão abre um leque de possibilidades para pensar os gradientes de autonomia, como pode-se ver nos trechos da narrativa a seguir:

Trazendo a infância pré-manicomial vivida ao lado do pai, regada a canções e programas dos anos 1980, Leão comunica sua realidade. E é no auge 
desse misto de sentimentos que Leão se impõe à existência: num rugido, que em palavras se tornam música, nosso ator proclama que 'Um leão está solto nas ruas, foi descuido do seu domador'. Cantou de modo inusitado e surpreendente uma música inteira! No dia do seu último aniversário, nasceu para quem estava ao seu lado, mas não o conhecia. Disse de sua existência e desnorteou todos aqueles que nela não criam. Leão, que poucas palavras proferia, passou a existir como aquele que canta alegremente e que, por descuido do seu domador, está livre nas ruas. (Narrativa Leão).

O personagem da vida real, no momento narrado acima, na RT onde morava, mostrou que sabia cantar e cantou, para surpresa de tantas pessoas que o acompanhavam havia tanto tempo, mas não o conheciam, quem sabe por estarem bastante ocupados em exercer o 'cuidado protocolar', atentos ao risco de o 'atendimento' dar errado e o trabalhador ser responsabilizado e culpabilizado por algo que não deveria ter ocorrido ${ }^{\mathbf{1 8}}$.

Sobre isso, Kinoshita ${ }^{\mathbf{1 5}}$ faz lembrar que a precondição para qualquer relação de troca, seja de afetos, mensagens ou bens, é o valor que se atribui à pessoa no campo social. Esse valor corresponderia ao seu poder contratual. A pessoa entendida como 'doente mental' tem, muitas vezes, anulado seu poder de contrato: "os bens dos loucos tornam-se suspeitos, as mensagens incompreensíveis, os afetos desnaturados, tornando impossível qualquer possibilidade de troca"15(70).

No decorrer dos itinerários, a escuta é o reconhecimento de algo que possivelmente já estava presente no cotidiano, mas, de modo escamoteado, faz com que essas expressões não reconhecidas da autonomia sejam alçadas à posição de novidade. É preciso lembrar com Saraceno citado por Lussi et al. ${ }^{18}$ que alterações na experiência do usuário com o seu entorno proporcionam ganhos na sua experiência com o transtorno mental. Cantar e ter reconhecido seu canto, suas mensagens, seus modos singulares de expressão e afetividade são um ato, por parte do beneficiário, de demarcação de sua existência que provoca na equipe de pesquisa, do serviço e mesmo entre seus próprios colegas de residência uma mudança no convívio e na forma como são concebidos aqueles que ocupam seu entorno.

Por outro lado, atentos aos atos sutis que dificultam a construção de diferentes graus de autonomia e que estão tantas vezes presentes no cotidiano das relações estabelecidas entre gestores/trabalhadores e as pessoas das quais cuidam, foi possível perceber que muitas vezes não se consegue ouvir o que 'dizem' - com ou sem palavras evidentes -, que frequentemente não foi possível investir em ações que estimulem a decisão/escuta sobre o que vestir ou comer, que tantas vezes os modos recorrentes de tratá-los como crianças compareceram às cenas observadas na pesquisa, ainda que esse ‘cuidado' tenha acontecido com a justificativa de preservar a integridade do outro. Isto é visto no trecho que segue:

Evita pedir cotonete, porque o cuidador da casa às vezes nega, por ele pedir 'direto... direto'. Seus objetos de higiene pessoal ficam guardados com os dos demais companheiros em um guarda-roupa a que não tem acesso direto, por isso precisa pedi-los quando necessário. (Narrativa Roberto Carlos).

Em geral, identifica-se a necessidade de problematizar em que medida a concepção de autonomia da gestão e dos trabalhadores da saúde mental se alinha à concepção neoliberal discutida acima. Pode-se afirmar que essa concepção resgata o olhar historicamente incapacitante para as pessoas com transtorno mental? Fica a pergunta para reflexão. No entanto, afirma-se que a caduca redução da loucura à 'doença mental' implica, inevitavelmente, um comportamento tutelar que, para além de infantilizá-las, dificulta ou até mesmo inviabiliza a produção de singularidades.

Como produzir potências em cenários tão melindrosos? Como encontrar caminhos possíveis para lidar com esses tantos gradientes de autonomia sem ser domador, controlador, limitador de vida? Caminhou-se todo o tempo 
da pesquisa e a cada escrita sobre ela com essas questões presentes em nos afetos dos pesquisadores.

\section{Considerações finais}

Discutiu-se sobre alguns gradientes de autonomia e exemplificou-se como as relações de interdependência comparecem no acompanhamento de itinerários de beneficiários do PVC e ajudam a romper com a lógica liberal de autonomia, tantas vezes utilizadas em momentos nos quais se precisou visibilizar que pessoas em sofrimento psíquico podem (e são) autônomas, em diferentes graus.

Destaca-se como a experiência da pesquisa ajudou nos processos de autonomia dos beneficiários com os quais se dialogou, considerando os tensionamentos, perguntas, olhares e discussões tidas no processo, seja no acompanhamento dos itinerários ou durante as reuniões do CAP, criado com o objetivo de ser um espaço de diálogo sobre o andamento da pesquisa, além de fomentar um olhar coletivo sobre o que estava sendo estudado ${ }^{19}$. Tal compreensão se deu pelo modo como se tomou o conceito de autonomia: não como antônimo de dependência, nem o sinônimo de liberdade absoluta, mas como a capacidade do sujeito de construir e lidar com sua rede de dependências ${ }^{\mathbf{1 4}}$. Assim, as pessoas são mais autônomas na mesma proporção em que são mais dependentes, pois essa é condição de possibilidade para o estabelecimento de novos ordenamentos, de novas normas para fazer seguir a vida ${ }^{15}$.

Entendendo que uma coconstituição de autonomia depende do próprio sujeito, mas também da coletividade, de condições externas ao sujeito, da existência de leis mais ou menos democráticas ${ }^{\mathbf{1 4}}$, questiona-se: como pensar esse campo de saberes/fazeres na atual conjuntura política de desmonte da política de saúde mental antimanicomial e de extinção de tantos direitos sociais adquiridos ao longo de anos de luta?

Os encontros potentes proporcionados pela pesquisa deram pistas sobre caminhos possíveis para seguir transformando o lugar social das pessoas beneficiárias do PVC, sendo capazes de posicioná-las, inclusive diante de si mesmas, dos seus familiares e trabalhadores/gestores dos 'lugares de cuidado' que elas frequentam, nas redes nas quais se inserem.

Nesse sentido, mesmo reafirmando a importância dos avanços inquestionáveis desde a saída dessas pessoas do Hospital Psiquiátrico, no que tange à possibilidade de gerirem suas vidas, reafirma-se que muito pode ser feito, que tutelar não é cuidar e que, lembrando Basaglia, o melhor espaço de reabilitação é a cidade. A desinstitucionalização, em sua radicalidade, ainda carece de uma reorientação das instituições e serviços, saberes e fazeres, como ensina Rotteli ${ }^{8}$, para que, finalmente, seja possível dizer que se cuida em liberdade.

\section{Colaboradores}

Silva A (0000-0003-1022-326X)*, Aleixo A (0000-0003-3084-0855)*, Silva C (00000002-8749-3295)*, Duarte J (0000-0002-42016831)* e Moraes M (0000-0002-3622-6824)* contribuíram igualmente para a elaboração do manuscrito 


\section{Referências}

1. Brasil. Lei n ${ }^{\circ} 10.216$, de 6 de abril de 2001. Dispõe sobre a proteção e os direitos das pessoas portadoras de transtornos mentais e redireciona o modelo assistencial de saúde mental. Diário Oficial da União. 9 Abr 2001.

2. Brasil. A Convenção sobre os Direitos das Pessoas com Deficiência - Versão Comentada [internet]. Brasília, DF: Secretaria Especial dos Direitos Humanos. Coordenadoria Nacional para Integração da Pessoa Portadora de Deficiência; 2008. [acesso em 2020 mar 1]. Disponível em: http://www.ampid.org.br/vl/versao-comentada-da-convencao-dos-direitos-da-pessoa-com-deficiencia-da-onu-tem-participacao-da-ampid/\#prettyPhoto.

3. Brasil. Lei ${ }^{\circ}$ 13.146, de 06 de julho de 2015. Institui a Lei Brasileira de Inclusão da Pessoa com Deficiência (Estatuto da Pessoa com Deficiência). Diário Oficial da União. 7 Jul 2015.

4. Brasil. Ministério da Saúde. Relatório de Gestão da Secretaria de Atenção à Saúde/SAS [internet]. Brasília, DF; 2015. [acesso em 2020 mar 1]. Disponível em: http://portalarquivos.saude.gov.br/images/pdf/2016/ marco/31/Relat--rio-de-Gest--o-da-SAS-2015-Final. pdf.

5. Kilsztajn S, Lopes ES, Lima LZ, et al. Leitos hospitalares e reforma psiquiátrica no Brasil. Cad. Saúde Pública [internet]. 2008 [acesso em 2020 mar 1]; 24(10). Disponível em: http://www.scielo.br/scielo.php?script=sci_arttext $\&$ pid $=$ S0102$-311 X 2008001000016 \& \operatorname{lng}=\mathrm{e}$.

6. Brasil. Ministério da Saúde. Portaria $n^{\circ} 3.088$, de 23 de dezembro de 2011. Institui a Rede de Atenção Psicossocial para pessoas com sofrimento ou transtorno mental e com necessidades decorrentes do uso de crack, álcool e outras drogas, no âmbito do Sistema Único de Saúde (SUS). Diário Oficial da União. 26 Dez 2011. [acesso em 2021 fev 8]. Disponível em: http://bvsms.saude.gov.br/bvs/saudelegis/gm/2011/ prt3088_23_12_2011_rep.html.
7. Brasil. Lei $n^{\circ} 10.708$, de 31 de julho de 2003. Institui o auxílio-reabilitação psicossocial para pacientes acometidos de transtornos mentais egressos de internações. Diário Oficial da União. 1 Ago 2003.

8. Rotelli F. A instituição negada. In: Nicacio MF. Desinstitucionalização. São Paulo: Hucitec; 1990.

9. Brasil. Ministério da Saúde. Saúde Mental em Dados - 12. Informativo eletrônico [internet]. 2015 [acesso em 2020 mar 1]; 10(12):1-48. Disponível em: https:// www.mhinnovation.net/sites/default/files/downloads/innovation/reports/Report_12-edicao-do-Saude-Mental-em-Dados.pdf.

10. Brito FSL, Montenegro AT. Andanças que cortam os caminhos da razão: as vivências insanas e a atuação da reforma psiquiátrica em Campina Grande - PB [dissertação]. Recife: Universidade Federal de Pernambuco; 2011. 198 p. [acesso em 2020 mar 1]. Disponível em: https://repositorio.ufpe.br/handle/123456789/7542.

11. Lecerda F, Guzzo RSL. Consciencia, vida cotidiana y alienación: Una interpretación a partir de la psicología social y del marxismo. Teoría y critica de la psicología [internet]. 2001 [acesso em 2020 ago 15]; (2):126-147. Disponível em: http://teocripsi.com/ojs/ index.php/TCP/article/view/89.

12. Geertz C. Nova luz sobre a antropologia. Rio de Janeiro: Jorge Zahar; 2001.

13. Campos RTK, Campos GWS. Tratado de Saúde Coletiva. Rio de Janeiro: Hucitec; Fiocruz; 2006.

14. Onocko RT, Campos GW. Co-construção de autonomia: o sujeito em questão. In: Campos GW, Minayo MC, Akerman M, et al. Tratado de Saúde Coletiva. Rio de Janeiro: Hucitec Fiocruz; 2006.

15. Kinoshita RT. Autopoiese e Reforma Psiquiátrica. São Paulo: Hucitec; 2016. (Coleção Saúde Loucura).

16. Dardot P, Laval C. A nova razão do mundo: ensaios sobre a sociedade neoliberal. São Paulo: Boitempo; 2018. 
17. Goffman E. Manicômios, prisões e conventos. 9. ed. São Paulo: Perspectiva; 2015.

18. Lussi IAO, Pereira MAO, Junior AP. A Proposta de Reabilitação Psicossocial de Saraceno: Um modelo de auto-organização. Rev. Latino-am Enfermagem [internet]. 2006 [acesso em 2020 mar 1]; 14(3):44656. Disponível em: http://www.scielo.br/pdf/rlae/ v14n3/v14n3a21.pdf.

19. Vaz BC, Lyra J, Cardoso AJC, et al. Produção compartilhada de conhecimentos em saúde mental: o Comitê de Acompanhamento de Pesquisa. Saúde soc [internet]. 2019 [acesso em 2020 mar 1]; 28(3):21-28. Dis- ponível em: https://www.scielosp.org/article/sausoc/2019.v28n3/21-28.

20. Dhanda A. Construindo um novo léxico dos direitos humanos: Convenção sobre os Direitos das Pessoas com Deficiência. Sur, Rev. int. direitos human [internet]. 2008 [acesso em 2020 fev 7]; 5(8):42-59. Disponível em: https://www.scielo.br/pdf/sur/v5n8/ v5n8a03.pdf.

Recebido em 03/03/2020

Aprovado em 21/09/2020

Conflito de interesses: inexistente

Suporte financeiro: não houve 